\title{
Comparison of resazurin microtiter assay performance and BACTEC MGIT 960 in the susceptibility testing of Brazilian clinical isolates of Mycobacterium tuberculosis to four first-line drugs
}

\author{
Marcelo Miyata ${ }^{1}$, Fernando Rogério Pavan ${ }^{1}$, Daisy Nakamura Sato ${ }^{1}$, \\ Leonardo Biancolino Marino ${ }^{1}$, Mario Hiroyuki Hirata ${ }^{2}$, Rosilene Fressati Cardoso ${ }^{3}$, \\ Fernando Augusto Fiúza de Melo ${ }^{4}$, Clarice Queico Fujimura Leite ${ }^{1}$ \\ ${ }^{1}$ Universidade Estadual Paulista, Faculdade de Ciências Farmacêuticas, Araraquara, SP, Brazil. \\ ${ }^{2}$ Universidade de São Paulo, Faculdade de Ciências Farmacêuticas, São Paulo, SP, Brazil. \\ ${ }^{3}$ Universidade Estadual de Maringá, Departamento de Análises Clínicas e Biomedicina, Maringá, PR, Brazil. \\ ${ }^{4}$ Instituto Clemente Ferreira, São Paulo, SP, Brazil.
}

Submitted: May 24, 2011; Approved: July 2, 2012.

\begin{abstract}
We assessed the performance of REMA in comparison with BACTEC MGIT 960 in the susceptibility testing of 80 Mycobacterium tuberculosis clinical isolates from Clemente Ferreira Institute against four drugs. REMA proved to be a rapid and accurate method, providing excellent correlation with BACTEC MGIT 960, with the exception of results for the ethambutol drug.
\end{abstract}

Key words: Mycobacterium tuberculosis, tuberculosis, drug susceptibility testing.

Tuberculosis (TB) remains a serious health problem, especially in underdeveloped and developing countries (Sanchotene et al., 2008). The rising incidence of drug resistant TB gives cause for concern around the world (WHO, 2010). Currently, Brazil occupies the 19th position among the 22 countries with the most cases of TB prevalence (WHO, 2010). The initial treatment for TB involves four drugs (MS/SVS, 2009): isoniazid (INH), rifampicin (RMP), pyrazinamide (PZA) and ethambutol (EMB). Big cities such as São Paulo have high population densities and the high human immunodeficiency virus (HIV) infection rates and large numbers of institutionalized and homeless people contribute to the high prevalence of TB (Ferrari et al., 2010). In this population, other factors contribute to the number of TB cases, such as irregular supply of drugs, unsuitable medical prescriptions and abandonment of treatment (Vareldzis et al., 1994). Low-cost, sustainable and accessible methods (Ferrari et al., 2010) that also exhibit high sensitivity, specificity and accuracy are indispensable in the TB control program, even as to achieve rapid detection of Mycobacterium tuberculosis in patients and characterization of drug resistance in the clinical isolates.
BACTEC MGIT 960 TB System is considered a simple and fast in-vitro diagnostic instrument, designed and optimized for the fast detection of mycobacteria from clinical specimens (Somoskövi et al., 2000). Resazurin Microtiter Assay (REMA) is a simple and inexpensive method utilizing resazurin, a redox indicator (Franzblau et al., 1998), to test the antimicrobial activity of drugs against clinical isolates of M. tuberculosis in low-income countries (Palomino et al., 2002).

We aimed to assess the performance of the REMA method in determining patterns of susceptibility to four first-line drugs in M. tuberculosis clinical isolates from Brazil, by comparison with BACTEC MGIT 960, taken as a gold standard employing Minimum Inhibition Concentration (MIC) estimation and cut-off values for each drug.

Eighty M. tuberculosis clinical isolates from Clemente Ferreira Institute located in São Paulo city were analyzed by the BACTEC MGIT 960 kit and REMA method to determine their susceptibility patterns to the drugs INH, RMP, streptomycin (STR) and EMB. Multi-drug resistance (MDR) was taken to be resistance to at least INH and RMP. Reference susceptibility patterns were obtained with

Send correspondence to M. Miyata. Universidade Estadual Paulista, Faculdade de Ciências Farmacêuticas, Araraquara, SP, Brazil. E-mail: marcelo_miyatabr@yahoo.com.br. 
BACTEC MGIT 960, performed at the Clemente Ferreira Institute, the TB reference center for São Paulo (SP) state, utilizing commercial kits supplied with fixed concentrations of $0.1 \mu \mathrm{g} / \mathrm{mL}, 1.0 \mu \mathrm{g} / \mathrm{mL}, 1.0 \mu \mathrm{g} / \mathrm{mL}$ and $5.0 \mu \mathrm{g} / \mathrm{mL}$, for INH, RMP, STR and EMB, respectively (Siddiqi et al., 2006).

REMA (Palomino et al., 2002) was carried out with a standardized bacterial inoculum, 96-well plate (Nunc Thermo Fisher Scientific, Waltham, MA) and resazurin (Sigma-Aldrich, Steinheim, Germany) as developing agent, to reveal bacterial viability and growth. Each test was carried out in triplicate. MIC was defined as the lowest concentration that inhibited $90 \%$ of $M$. tuberculosis growth (Palomino et al., 2002). Comparative analysis between the BACTEC MGIT 960 kit and REMA data allowed the breakpoint concentration to be determined with the MedCalc Software (Mariakerke, Belgium), by means of the Receiver Operating Characteristic (ROC) curve. Accuracy of REMA was evaluated from the area under the curve $($ AUC): $1-0.9=$ excellent; $0.9-0.8=$ good; $0.8-0.7=$ moderate and $<0.7$ weak correlation.

Among the eighty M. tuberculosis clinical isolates, BACTEC MGIT 960 detected 57 (71.2\%) INH-resistant isolates, 49 (61.2\%) RMP-resistant isolates, 29 (36.2\%) STR-resistant isolates, 21 (26.2\%) EMB-resistant isolates and $48(60 \%)$ MDR isolates (Table 1). REMA determined the MIC values and the MedCalc Software determined cut-off values for each drug, based on the ROC curve concept (Table 1). ROC curve analysis resulted in sensitivity of $100 \%, 97.2 \%, 92.6 \%$ and $89.5 \%$, specificity of $100 \%$, $100 \%, 90 \%$ and $56.4 \%$ and accuracy levels of excellent, excellent, good and reasonable, with cut-off values of 0.0625 $\mu \mathrm{g} / \mathrm{mL}, 0.125 \mu \mathrm{g} / \mathrm{mL}, 0.25 \mu \mathrm{g} / \mathrm{mL}$ and $8 \mu \mathrm{g} / \mathrm{mL}$ for INH, RMP, STR and EMB, respectively. Once the values had been fixed, all clinical isolates were classified as sensitive or resistant, according to their MIC values. REMA results demonstrated that, among the $80 \mathrm{M}$. tuberculosis clinical isolates, $63(75 \%)$ were INH-resistant, $41(51.2 \%)$ were RMP-resistant, $43(53.7 \%)$ were STR-resistant and 47 (58.7\%) were EMB-resistant. Simultaneous resistance to INH and RMP was found in $39(48.7 \%)$ isolates, thus considered as MDR (Table 1). Some authors $(5,3,8)$ based on these observations have proposed the existence of three categories of susceptibility: susceptible, partially resistant (isolates with MICs close to the cut-off value) and resistant (Mengatto et al., 2006).

Based on a sub-classification (Palomino et al., 2002, Tudó et al., 2010) of resistant isolates by REMA, a division was made between high and low resistance, with cut-off values of $1 \mu \mathrm{g} / \mathrm{mL}, 2 \mu \mathrm{g} / \mathrm{mL}, 1 \mu \mathrm{g} / \mathrm{mL}$ and $16 \mu \mathrm{g} / \mathrm{mL}$, for INH, RMP, STR and EMB, respectively. As result of this sub-classification, the resistant isolates were divided into: 53 (84.1\%) INH high-resistance and 10 (15.8\%) INH lowresistance (Figure 1a); 30 (73.1\%) RMP high-resistance and $11(26.8 \%)$ RMP low-resistance (Figure 1b); 19
Table 1 - Results for $80 \mathrm{M}$. tuberculosis clinical isolates analyzed by BACTEC MGIT 960 and REMA.

\begin{tabular}{lccc}
\hline Drug & $\begin{array}{c}\text { BACTEC MGIT 960 } \\
\text { resistance }\end{array}$ & $\begin{array}{c}\text { REMA resis- } \\
\text { tance }\end{array}$ & $\begin{array}{c}\text { Statistical analysis } \\
\text { cut-off value }(\mu \mathrm{g} / \mathrm{mL})\end{array}$ \\
\hline INH & $57(71.2 \%)$ & $63(75 \%)$ & $>0.0625$ \\
RMP & $49(61.2 \%)$ & $41(51.2 \%)$ & $>0.125$ \\
STR & $29(36.2 \%)$ & $43(53.7 \%)$ & $>0.25$ \\
EMB & $21(26.2 \%)$ & $47(58.7 \%)$ & $>8$ \\
MDR & $48(60 \%)$ & $39(48.7 \%)$ & \\
\hline
\end{tabular}

(44.1\%) STR high-resistance and 24 (55.8\%) STR lowresistance (Figure 1c) and 40 (85.1\%) EMB high-resistance and $7(14.8 \%)$ EMB low-resistance (Figure 1d).

The high percentage of MDR isolates found in this study was probably related to the main objective of the Clemente Ferreira Institute, to assist TB patients with a difficulty history of TB treatment. Studies performed in the period from 1995 to 1998 also revealed a high prevalence of MDR cases (Melo et al., 2003), characterized mainly by treatment failure and abandoned and inappropriate prescriptions (Jardim et al., 2001).

Drug susceptibility patterns of M. tuberculosis clinical isolates were tested by REMA because this methodology enables the resistance level to be assessed with more precision in terms of MIC values (Heifets, 1988). The correct evaluation of the MIC is important because if resistant strains are classified as sensitive, the treatment will not reduce the patient's suffering and this resistant strain will spread to other people. Besides that, if sensitive strains are classified as resistant, the patient will be treated with unnecessarily toxic and expensive drugs, resulting in overload of the health system (Ahmad et al., 2007) and patients with collateral effects. Cut-off values found in this paper were lower than those reported by other authors (Montoro et al., 2005 , Jadaun et al., 2007). Such differences probably arise bacterial populations coming from different sources, with different susceptibility patterns and proportions of resistant isolates in each study, resulting in different cut-off values for each drug. Despite the discrepancies found, the authors agree that REMA is a fast method for MDR strain detection (Montoro et al., 2005, Jadaun et al., 2007, Rivoire et al., 2007).

For INH, there were no discordant results between REMA and BACTEC MGIT 960 (Table 2) and the sensitivity and specificity of REMA were excellent. Similar results are found in the literature (Palomino et al., 2002, Luna-Herrera et al., 2003, Montoro et al., 2005, Mengatto et al., 2006, Nateche et al., 2006, Rivoire et al., 2007), indicating the viability of REMA in testing patterns of susceptibility to INH, even though cut-off values range between 0.0625 and $0.225 \mu \mathrm{g} / \mathrm{mL}$ and different results for sensitivity and specificity are found in the literature. RMP showed one discrepancy (1 false sensitive) (Table 2), resulting in a 

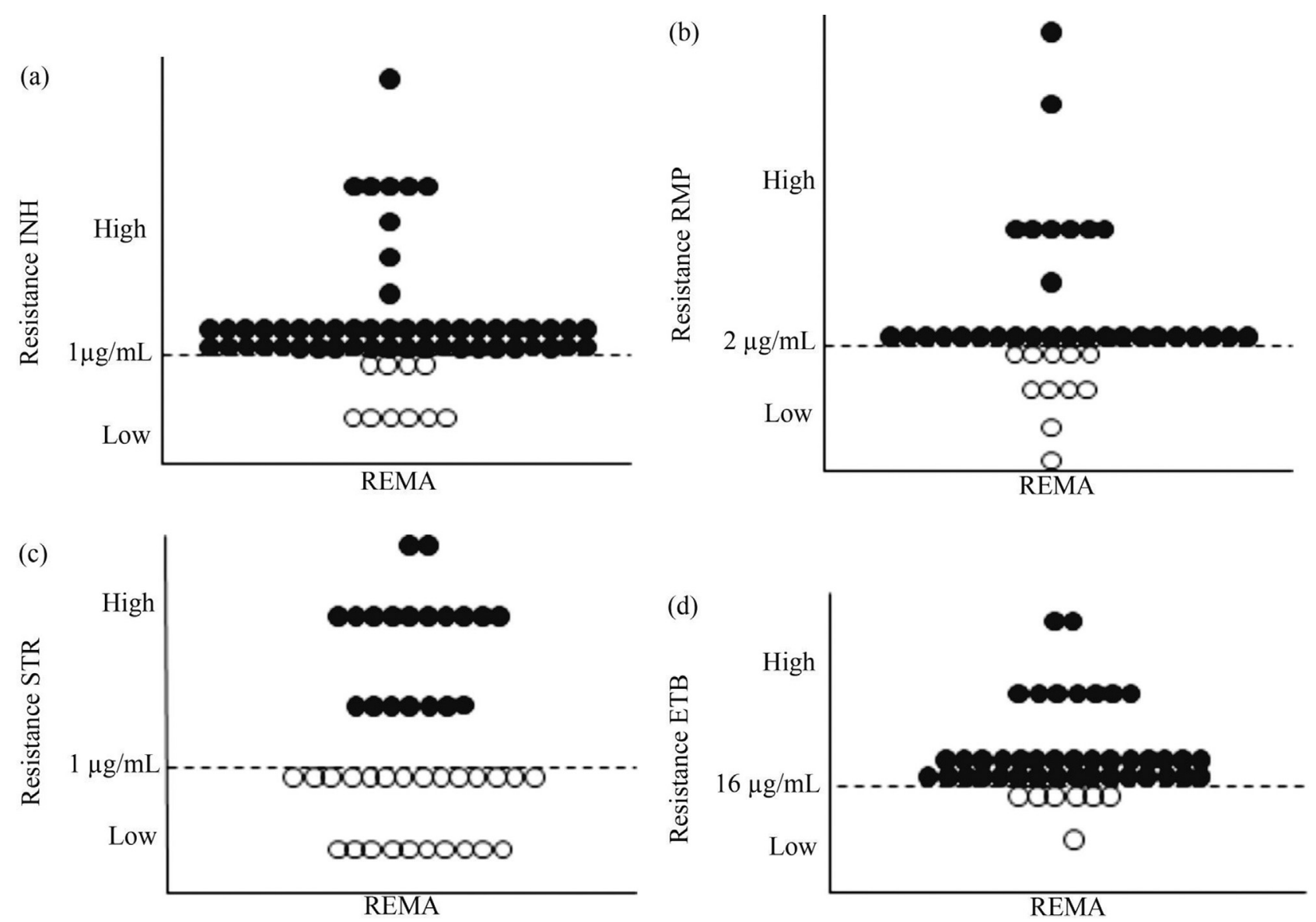

Figure 1 - Sub-classification within resistant isolates by REMA. (a) INH-resistant isolates. (b) RMP-resistant isolates. (c) STR-resistant isolates. (d) EMB-resistant isolates. Full circles represent high-resistant isolates and empty circles represent low-resistant isolates.

lower sensitivity than that of INH, but with the same specificity and also excellent correlation, with similar results for sensitivity $(95 \%)$ and specificity $(100 \%)$ in the literature (Palomino et al., 2002, Luna-Herrera et al., 2003, Montoro et al., 2005, Nateche et al., 2006, Rivoire et al., 2007), as well as excellent correlation (Palomino et al., 2002, LunaHerrera et al., 2003, Mengatto et al., 2006). For STR, there were 4 discordant results $(1$ false resistant and 3 false sensitive) (Table 2), resulting in lower values of both sensitivity and specificity and excellent correlation, with similar published results ranging between 88.5 and $100 \%$ (Palomino et al., 2002, Luna-Herrera et al., 2003, Montoro et al., 2005, Nateche et al., 2006, Rivoire et al., 2007), as well an excel-

Table 2 - Results from 80 M. tuberculosis clinical isolates analyzed by BACTEC MGIT 960 and REMA showing numbers of agreements and disagreements results.

\begin{tabular}{|c|c|c|c|c|c|c|c|c|}
\hline \multirow[b]{2}{*}{ REMA } & \multicolumn{2}{|c|}{ INH } & \multicolumn{2}{|c|}{ RMP } & \multicolumn{2}{|c|}{ STR } & \multicolumn{2}{|c|}{ EMB } \\
\hline & $\mathrm{R}$ & $\mathrm{S}$ & $\mathrm{R}$ & $\mathrm{S}$ & $\mathrm{R}$ & $\mathrm{S}$ & $\mathrm{R}$ & $\mathrm{S}$ \\
\hline $\mathrm{R}$ & 41 & 0 & 35 & 0 & 26 & 3 & 13 & 23 \\
\hline S & 0 & 16 & 1 & 21 & 1 & 27 & 3 & 18 \\
\hline Total & 41 & 16 & 36 & 21 & 27 & 30 & 16 & 41 \\
\hline
\end{tabular}

lent correlation (Luna-Herrera et al., 2003). EMB showed 26 discordant results ( 3 false resistant and 23 false sensitive) (Table 2), resulting in a lower value of sensitivity, low value of specificity (Montoro et al., 2005) and reasonable correlation; previous sensitivity results ranged between 92 and $98 \%(6,8,13)$, specificity results between 98 and $100 \%$ (Luna-Herrera et al., 2003, Jadaun et al., 2007) and correlation was reasonable (Madison et al., 2002). According to the literature, the INH high-resistance isolates showed similar results to those of Palomino et al. (Palomino et al., 2002), RMP and STR high-resistance isolates showed worse results than Palomino et al. (2002) and Tudó et al. (2010), respectively, and EMB high-resistance isolates showed similar results to those of Siddiqi et al. (1985).

STR and EMB, but especially EMB, have important factors that may have contributed to the discrepancies in the results: (i) a small proportion of drug-resistant strains in the population studied, (ii) substantial differences in the volume of medium utilized by the two methods, and (iii) different periods of incubation, which may result in different degrees of degradation of the drugs (Mengatto et al., 2006). Partially resistant isolates with borderline MICs were not found in this study, so that MIC values were well defined as susceptible or resistant. Furthermore, some authors have 
shown that these "borderline" cultures, more frequently associated with EMB resistance, have classically caused problems in the interpretation of EMB susceptibility testing (Siddiqi et al., 1985), adversely affecting the overall performance of the assay. On the other hand, for STR, a low level of sensitivity was obtained.

Finally, our results demonstrate that REMA is a rapid method for the determination of the susceptibility to drugs of $M$. tuberculosis clinical isolates in reference laboratories such as Clemente Ferreira Institute, which shows a high level of accuracy when compared with BACTEC MGIT 960, except in tests with the drug EMB.

\section{Acknowledgments}

We thank CNPQ and FAPESP for financial support and the Clemente Ferreira Institute for M. tuberculosis clinical isolates.

\section{References}

Ahmad S, Jaber AA, Mokaddas E (2007) Frequency of embB codon 306 mutations in ethambutol-susceptible and -resistant clinical Mycobacterium tuberculosis isolates in Kuwait. Tuberculosis 87:123-129.

Ferrari ML, Telles MA, Ferrazoli L, Levy CE, Villares MC, Moretti ML, Resende MR (2010) Susceptibility of Mycobacterium tuberculosis to first-line antimycobacterial agents in a Brazilian hospital: assessing the utility of the tetrazolium (MTT) microplate assay. Mem Inst Oswaldo Cruz 105:661-664.

Franzblau SG, Witzig RS, Mclaughlin JC, Torres P, Madico G, Hernandez A, Degnan MT, Cook MB, Quenzer VK, Fergunson RM, Gilman RH (1998) Rapid, Low-Technology MIC Determination with Clinical Mycobacterium tuberculosis Isolates by Using the Microplate Alamar Blue Assay. J Clin Microbiol 36:362-366.

Heifets LB (1988) Qualitative and quantitative drug susceptibility tests in mycobacteriology. Am Rev Respir Dis 137:12171222.

Heifets LB, Lindholm-Levy PJ, Flory M (1990) Bactericidal activity in vitro of various rifamycins against Mycobacterium avium and Mycobacterium tuberculosis. Am Rev Respir Dis 141:626-630.

Jadaun GPS, Agarwal C, Sharma H, Ahmed Z, Upadhyay P, Faujdar J, Gupta AK, Das R, Gupta P, Chauhan DS, Sharma VD, Katoch VM (2007) Determination of ethambutol MICs for Mycobacterium tuberculosis and Mycobacterium avium isolates by resazurin microtitre assay. J Antimicrob Chemother 60:152-155.

Jardim PCR, Zamarioli LA, Coelho AGV, Figueiredo TR, Rozman MA (2001) Resistência do Mycobacterium tuberculosis às drogas do município de São Vicente. Rev Inst Adolfo Lutz 60:119-123.

Luna-Herrera JL, Cabrera MG, Maldonado RP, Moreno JAE, Lopes JT, Pascual FQ, Polando RD, Franzblau SG (2003) Use of receiver operating characteristic curves to assess the performance of a microdilution assay for determination of drug susceptibility of clinical isolates of Mycobacterium tuberculosis. Eur J Clin Microbiol Infect Dis 22:21-27.
Madison B, Robinson-Dunn B, George I, Gross W, Lipman H, Metchock B, Sloutsky A, Washabaugh G, Mazurek G, Ridderhof J (2002) Multicenter evaluation of ethambutol susceptibility testing of Mycobacterium tuberculosis by agar proportion and radiometric methods. J Clin Microbiol 40:3976-3979.

Melo FAM, Afiune JB, Neto JI, Almeida EAA, Spada DTA, Antelmo ANL, Cruz ML (2003) Aspectos epidemiológicos da tuberculose multiresistente em serviço de referência na cidade de São Paulo. Ver Soc Bras Med Trop 36:27-34.

Mengatto L, Chiani Y, Imaz MS (2006) Evaluation of rapid alternative methods for drug susceptibility testing in clinical isolates of Mycobacterium tuberculosis. Mem Inst Oswaldo Cruz 101:535-542.

MS/SVS - Ministério da Saúde do Brasil/Secretaria de Vigilância em Saúde/Departamento de Vigilância Epidemiológica (2009) Programa Nacional de Controle da Tuberculose. Nota técnica sobre as mudanças no tratamento da tuberculose no Brasil para adultos e adolescentes. Available from: portal.saude.gov.br/portal/arquivos/pdf/ nota_tecnica_versão_28_de_agosto_v_5.pdf

Montoro E, Lemus D, Echemendia M et al. (2005) Comparative evaluation of the nitrate reduction assay, the MTT test, and the resazurin microtitre assay for the drug susceptibility testing of clinical isolates of Mycobacterium tuberculosis. J Antimicrob Chemother 55:500-505.

Nateche F, Martin A, Baraka S, Palomino JC, Khaled S, Portaels F (2006) Application of the resazurin microtitre assay for detection of multidrug resistance in Mycobacterium tuberculosis in Algiers. J Med Microbiol 55:857-860.

Palomino JC, Martin A, Camacho M, Guerra H, Swings J, Portaels F (2002) Resazurin microtiter assay plate: simple and inexpensive method for detection of drug resistance in $\mathrm{My}$ cobacterium tuberculosis. Antimicrob Agents Chemother 46: 2720-2722.

Rivoire N, Ravololonandriana P, Rasolonavalona T, Martin A, Portaels F, Ramarokoto H, Rasolofo Razanamparany V (2007) Evaluation of the resazurin assay for the detection of multidrug-resistant Mycobacterium tuberculosis in Madagascar. Int J Tuberc Lung Dis 11:683-688.

Sanchotene KO, von Groll A, Ramos D, Scholante AB, Honscha G, Valença M, Scaini C.J.; da Silva PEA (2008) Comparative evaluation of the nitrate reductase assay and the resazurin microtitre assay for drug susceptibility testing of $M y$ cobacterium tuberculosis against first line anti-tuberculosis drugs. Braz J Microbiol 39:16-20.

Siddiqi SH, Hawkins JE, Laszlo A (1985) Interlaboratory drug susceptibility testing of Mycobacterium tuberculosis by a radiometric procedure and two conventional methods. J Clin Microbiol 22:919-923.

Siddiqi SH (BD Fellow, Sparks, Maryland, USA); Rüsch-Gerdes S (National Reference Center for Mycobacteria, Borstel, Germany) (2006) BACTEC MGIT 960 TB System Manual.

Somoskövi A, Ködmön C, Lantos A, Bártfai Z, Tamási L, Füzy J, Magyar P (2000) Comparison of recoveries of Mycobacterium tuberculosis using the automated BACTEC MGIT 960 System, BACTEC 460 TB System and Lowenstein-Jensen Medium. J Clin Microbiol 38:2395-2397.

Tudó G, Rey E, Borrell S, Alcaide F, Codina G, Coll P, MartínCasabona N, Montemayor M, Moure R, Orcau A, Salvadó M, Vicente E, González-Martín J (2010) Characterization of 
mutations in streptomycin-resistant Mycobacterium tuberculosis clinical isolates in the area of Barcelona. J Antimicrob Chemother 65:2341-2346.

Vareldzis BP, Grosset J, de Kantor I, Crofton J, Laszlo A, Felten M, Raviglione MC, Kochi A (1994) Drug-resistant tuberculosis: Laboratory issues. World Health Organization recommendations. Tubercle Lung Dis 75:1-7.
WHO Library Cataloguing-in-Publication Data (2010) Global tuberculosis Control: surveillance, planning, financing: WHO report 2008. [WHO/HTM/TB/2008.393]. 2008, 294 pp.

http://www.who.int/tb/publications/global_report/en/

All the content of the journal, except where otherwise noted, is licensed under a Creative Commons License CC BY-NC. 